\title{
CD4 CD25 T Cells in Children with Recent Onset Type 1 Diabetes
}

\author{
MARWA FATHY, M.Sc.*; IBRAHIM IBRAHIM M. EL ARABY, M.D.*; NANCY M. EL GUINDY, M.D.** and \\ GHADA M. ANWAR, M.D.**
}

The Department of Pediatrics, Faculty of Medicine, Alexandria and MUST* and Cairo** Universities

\begin{abstract}
Background: Type 1 diabetes (T1D) results from T-cellmediated autoimmune destruction of the insulin-producing pancreatic islet Beta cells. This breakdown of immunological self-tolerance results in auto reactivity to islet self-antigens. This requires genetic susceptibility as well as environmental factors (gene environmental interaction). It is believed that numerical and functional balance between killer cells (CD4+ and $\mathrm{CD} 8+$ ) and regulatory T-cells in the pancreatic infiltrate determines the extent of Beta cell destruction.
\end{abstract}

Aim of Study: To study the number and function of Treg CD4+ CD25+ T-cells in infants and children with recent onset type 1 diabetes and to compare the results with the Treg CD4+ CD25+ T-cells in the siblings of the diabetic child and control subjects.

Patients and Methods: This study was performed on60 patients meeting the diagnostic criteria of type I diabetes, together with 20 children of their non diabetic siblings were recruited at the Diabetes Endocrine and Metabolism Pediatric Unit (DEMPU) at Cairo University Children's Hospital in the period from December 2011 to October 2012. In addition to 20 children with age and sex-matched, none of whom had either a personal or family history of diabetes or other autoimmune pathologies as control were included in the study.

Results: Show no statistically significant relation of CD4 CD25 T-lymphocytes to age, anthropometric measures (weight \& height), laboratory data including HBA1C, lipid profile or thyroid function tests, the insulin dose and the severity of the case presentation (whether classic onset or DKA). Also there was no statistically significant difference between the 3 groups (diabetic - non diabetic siblings - controls) regarding CD4CD25 T- lymphocytes levels by the one-way ANOVA test.

Conclusion: The sensitivity of CD4 CD25 T-lymphocytes in case of type 1 diabetes was $60 \%$ and the specificity was 47\%. The PPV (positive predictive value) and the NPV (negative predictive value) were $55 \%$ and $67 \%$ respectively. Such results conclude that CD4 CD25 T-lymphocytes cannot be taken as a valid marker in case of type I diabetes.

Key Words: CD4+CD25+ T Cells - Recent onset Type 1 diabetes.

Correspondence to: Dr. Marwa Fathy, The Department of Pediatrics, Faculty of Medicine, Alexandria and MUST University

\section{Introduction}

TYPE I diabetes is increasing in incidence in developed countries. Diabetes arises from a breakdown of tolerance to islet antigens, resulting in $\mathrm{T}$ cell-driven destruction of the islet cells and concomitant hyperglycemia [1]. Less is known about the nature and function of these T-cells, the cause of the loss of tolerance to islet autoantigens, why the immune system apparently fails to suppress autoreactivity, and whether (or which) autoantigen (s) are critically involved in the initiation or progression of the disease [2]. Cellular autoimmunity is a difficult study subject, but it has been a worthwhile quest to unravel the role of T-cells in the pathogenesis of Type 1 diabetes.

Lindley et al., [3] hypothesized that a deficiency in the CD4+ CD25+ Treg population or its function could contribute to the lack of self-tolerance evident in patients with type 1 diabetes.

Naturally occurring FOXP3+CD4+CD25 regulatory $\mathrm{T}$ cells (Tregs) play an important role in tolerance, suppressing autoreactive CD4+ effector $T$ cell activity. In both recent-onset T1D patients and B cell antibody positive at-risk individuals, there was an increased apoptosis and decreased function of polyclonal Tregs with a decline in suppressive potential of these cells in the periphery. The fact that both hyperglycemic $\mathrm{T} 1 \mathrm{D}$ subjects and normoglycemic (at-risk) subjects showed this abnormality suggests that Treg apoptosis is more a precursor to, rather than a consequence of diabetes [4].

Pancreatic $\mathrm{P}$-cell destruction is associated with the presence of islet cell autoantibodies directed against the autoantigens including insulin, glutamic acid decarboxylase GAD65, and the islet tyrosine phosphatase IA-2. Autoreactive T-cells that recog- 
nize these and other islet autoantigens have been identified and are thought to play a direct role in type 1 diabetes immunopathogenesis [2]. Also Herold et al., [5] proposed an evidence that administration of therapeutic agents that inhibit T-cell function delays disease progression.

It seems that the process of $\beta$-cell destruction usually lasts a long time until it reaches the point when exogenous insulin is needed (T1D onset). After onset, however some patients enter the "honeymoon period", a transient period that may last for up to 1 year, when the need for exogenous insulin decreases. The disease status (pre-diabetes and honeymoon period) has been acknowledged as the most important immunological intervention period that can postpone the destruction of $\beta$-cells. Riley et al., [6] stated that one of the most immunologic promising interventions is through Treg cell infusion therapy during this period. They confirmed that approaches towards this goal are available: (1) conversion of non-regulatory CD4+CD25- T cells into induced Treg (iTreg) cells; (2) in vivo expansion of a pure subset of thymically derived (natural CD4+CD25+) Treg cells.

\section{Aim of work:}

The purpose is to study the number and function of Treg CD4+ CD25+ T-cells in infants and children with recent onset type 1 diabetes and to compare the results with the Treg CD4+ CD25+ T-cells in the siblings of the diabetic child and control subjects. Then to correlate findings with demographic data, clinical presentation, therapy and associated conditions in type 1 diabetic children.

\section{Patients and Methods}

\section{Patients populations and sampling protocol:}

All aspects of this study were approved by Cairo University Institutional Review Board. Patients, non diabetic siblings and controls were enrolled after obtaining informed consent from the parents. Sixty patients meeting the diagnostic criteria of type I diabetes, together with twentychildren of their non diabetic siblings were recruited at the Diabetes Endocrine and Metabolism Pediatric Unit (DEMPU) at Cairo University Children's Hospital in the period from December 2011 to October 2012. In addition to twenty children with age and sex-matched, none of whom had either a personal or family history of diabetes or other autoimmune pathologies as control were included in the study.

\section{Inclusion criteria:}

Definite diagnosis of type I diabetes according to the definition of the WHO criteria that defines this form of diabetes with permanent insulinopenia prone to ketoacidosis, result from a cellularmediated autoimmune destruction of the beta cells of the pancreas.

- On insulin replacement therapy.

- Age range up to 18 years.

- Diabetic duration less than 6 month.

\section{Exclusion criteria:}

- Children with secondary diabetes mellitus (DM).

- Children with type 2 DM.

- Evidence of active infection requiring antibiotic therapy or other concurrent diseases.

- Other autoimmune disease.

Methodology:

All included patients will be subjected, to:

\section{I- Clinical assessment:}

- Complete history taking including family history of diabetes, onset of the disease, clinical presentation at onset, regimen and dose of insulin therapy, glycemic control, feeding pattern and the presence of any complications.

- Thorough clinical examination including blood pressure, detection of any complication or associated condition.

II- Routine laboratory examination for the patients: - Mean HbA1c as indicator of glycemic control.

- Lipid profile and thyroid function tests.

\section{III- Special investigations:}

Venous blood sample for detection of CD4 CD25 T-cells subpopulation. The venous blood was taken using sterile tubes containing an EDTA salt as the anticoagulant. The samples were kept at room temperature $\left(18-25^{\circ} \mathrm{C}\right)$ and not shaken The samples were analyzed within 24 hours of venipuncture.

\section{Flow cytometric detection of CD4 CD25 T cells:}

It is fluorochrome-conjugated antibody that permits the identification and numeration of cell populations expressing the CD4 antigen and CD25 antigen present in human biological samplesusing flow cytometry. This test is based on the ability of specific monoclonal antibodies to bind to the antigenic determinants expressed by leucocytes. The flow cytometer measures light diffusion and the 
fluorescence of cells. The fluorescence of the delimited cells is analyzed inorder to distinguish the positively stained events from the unstained ones. The results are expressed as a percentage of positive events in relation to all the events acquired by the gating.

\section{Statistical analysis:}

Statistical package for social sciences (SPSS), version 16 was used for data analysis to estimate frequency distribution, percentage distribution, range, mean, standard deviations and correlation coefficient. One-way ANOVA test analysis was used to detect the statistical significance differences between 3 groups (diabetic non diabetic sibling control group) regarding CD4 CD25 T lymphocytes levels. A $p$-value of $\leq 0.05$ denoted the presence of a statistically significant difference.

\section{Results}

This study was conducted on 100 child including 60 diabetic children with new onset diabetes (within the first 6 months of diagnosis) \& 20 non diabetic sibling of previous patients \& 20 healthy controls.

There was no statistically significant difference between diabetic group, non diabetic sibling group and control group as regard the age and gender Table (1).

Table (1): Comparison between the studied groups regarding age \& sex.

\begin{tabular}{ccccc}
\hline Variables & $\begin{array}{c}\text { Diabetic } \\
\text { patients } \\
\mathrm{N}=60\end{array}$ & $\begin{array}{c}\text { Non diabetic } \\
\text { Siblings } \\
\mathrm{N}=20\end{array}$ & $\begin{array}{c}\text { Controls } \\
\mathrm{N}=20\end{array}$ & $p$ \\
\hline Age (yrs): & & & & \\
Mean & $7.6 \pm 3$ & $5.8 \pm 3$ & $8.5 \pm 4$ & $>0.05$ \\
Range & $1.08-14$ & $0.16-11.5$ & $0.5-18$ & $\mathrm{NS}$ \\
Gender: & & & & \\
Male & $21(35 \%)$ & $8(40 \%)$ & $11(55 \%)$ & $>0.05$ \\
Female & $39(65 \%)$ & $12(60 \%)$ & $9(45 \%)$ & $\mathrm{NS}$ \\
\hline
\end{tabular}

The current results showed that $58.3 \%$ of the diabetic group were presented by classic symptoms (polyuria, polydepsia, abdominal pain \& weight loss), while DKA was the presenting manifestation in $41.7 \%$ of patients. No significant relationship between the mode of presentation (whether DKA or classic presentation) and CD4 CD25 T cell level by using $t$-test (Fig. 1).

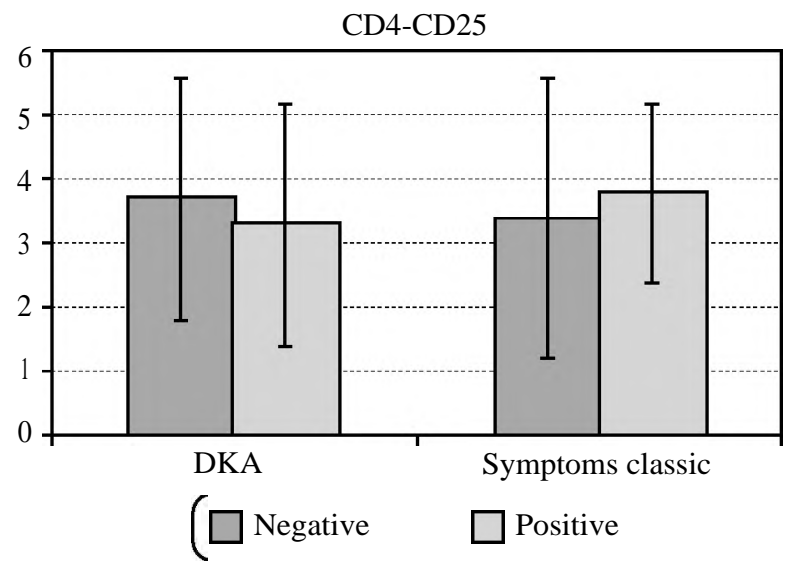

Fig. (1): Relation between CD4 CD25 T cell level to presenting manifestations in diabetic patients. $p>0.05 \mathrm{NS}$

The laboratory investigations of diabetic patients included in the study are summarized in Table (2). Four cases out of the diabetic group had abnormal lipid profile: Hypercholesterolemia in 1 case, low HDL in 2 cases, and high LDL in 1 case.

Table (2): Laboratory data of the studied diabetic patients.

\begin{tabular}{lll}
\hline Variables & Mean & \pm SD \\
\hline HBA1C gm\% & 9.2 & 2.8 \\
Cholesterol mg/dl & 136 & 19.2 \\
LDL mg/dl & 62.7 & 14 \\
HDL mg/dl & 57.8 & 12.8 \\
TG mg/dl & 58 & 12.5 \\
TSH uIU/dl & 1.8 & 0.6 \\
T4 mg/dl & 1.3 & 0.4 \\
\hline
\end{tabular}

There was no statistically significant difference between the 3 groups (diabetic - non diabetic siblings - control group) regarding CD4 CD25 Tlymphocytes levels by the one-way ANOVA test. The mean values of CD4 CD25 ratio among diabetic group was $3.6 \pm 1.6$ with a range of values $0.2-7.1$, in non diabetic siblings ratio was $4 \pm 1.7$ with a range of values 2.1-7.7, while in control group ratio was $3.9 \pm 1.3$ with a range of values 0.69-6.5 as shown in Fig. (2).

CD4-CD25 cell level

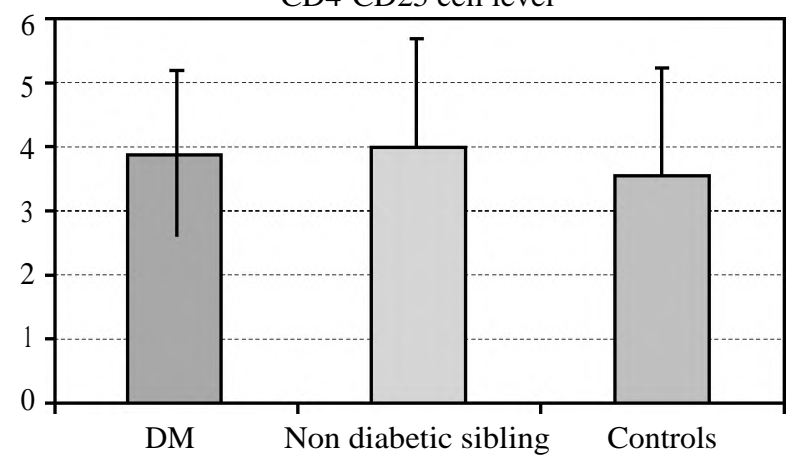

Fig. (2): Comparison of CD4-CD25 cell level in the studied groups. $p>0.05 \mathrm{NS}$. 
Males had a higher CD4 CD25 levels than females and difference was significant $(p>0.05$ NS) among the diabetic group but not in the other two groups, as shown in Fig. (3).

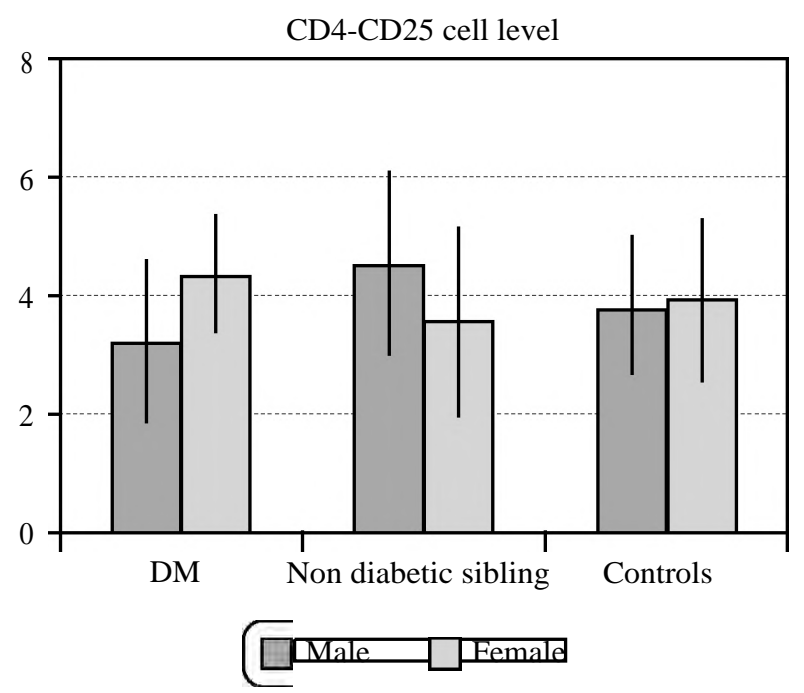

Fig. (3): Relation between CD4-CD25 versus gender among studied groups. $p>0.05$ NS.

Table (3): Correlation of CD4-CD25 cell level to demographic, clinical, laboratory data, insulin therapy in diabetic patients

\begin{tabular}{lll}
\hline \multirow{2}{*}{ Variables } & \multicolumn{2}{c}{ CD4-CD25 } \\
\cline { 2 - 3 } & \multicolumn{2}{c}{$r p$} \\
\hline Age (years) & 0.13 & $>0.05$ \\
Duration of onset (days) & 0.22 & $>0.05$ \\
Height $(\mathrm{cm})$ & -0.09 & $>0.05$ \\
Weight $(\mathrm{kg})$ & 0.12 & $>0.05$ \\
HBA1C gm\% & -0.24 & $>0.05$ \\
Cholesterol mg/dl & 0.22 & $>0.05$ \\
LDL mg/dl & 0.02 & $>0.05$ \\
HDL mg/dl & -0.11 & $>0.05$ \\
TG mg/dl & 0.14 & $>0.05$ \\
TSH uIU/ml & 0.20 & $>0.05$ \\
T4 mg/dl & -0.07 & $>0.05$ \\
Insullin dose u/kg/day & 0.06 & $>0.05$ \\
Severity of presentations & 0.12 & $>0.05$ \\
\hline
\end{tabular}

Our results did not show statistically significant relation of CD4 CD25 T-lymphocytes to age, anthropometric measures (weight \& height) and the laboratory data including HBA1C, lipid profile or thyroid profile.

Neither the insulin dose nor the severity of the case presentation (whether classic onset or DKA) had any statistically significant correlation with CD4 CD25 T-lymphocytes level.
Table (4): Validity of CD4-CD25 in case of type 1 diabetes.

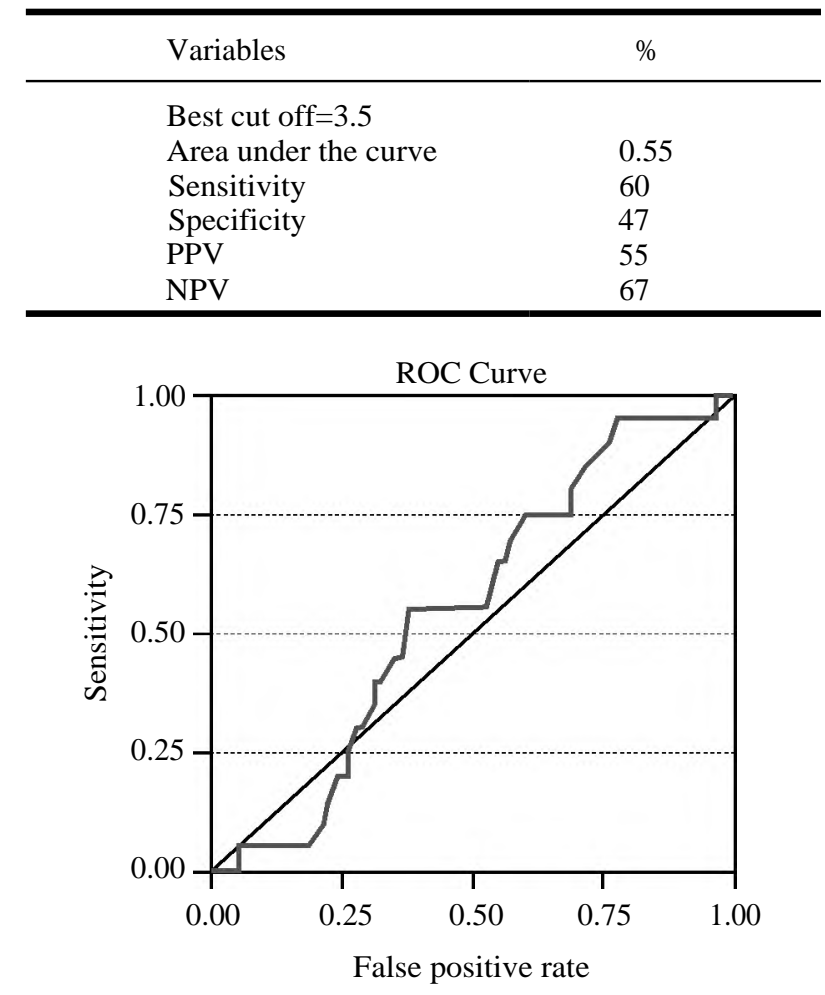

\section{Discussion}

Regulatory $\mathrm{T}$ cells (Tregs) are an immunosuppressive subgroup of CD4+ T cells which are identified by the expression of forkhead box protein P3 (Foxp3). The modulation capacity of these immune cells holds an important role in both transplantation and the development of autoimmune diseases. These cells are the main mediators of self-tolerance and are essential for avoiding excessive immune reactions. Tregs play a key role in the induction of peripheral tolerance that can prevent autoimmunity, by protecting self-reactive lymphocytes from the immune reaction. In contrast to autoimmune responses, tumor cells exploit Tregs in order to prevent immune cell recognition and anti-tumor immune response during the carcinogenesis process [7]

Thus Tregs represent naturally occurring CD4 cell population expressing $\mathrm{CD} 25$ antigen that arises from the thymus and seeds in the periphery creating a cohort of cells with profound T-cell immunosuppressive qualities [8]. In the present study, our results show that $\mathrm{CD} 4 \mathrm{CD} 25$ regulatory $\mathrm{T}$ cells has no role in type I diabetes.

Immunopathogenesis and the sensitivity of CD4 CD25 T-lymphocytes in case of type 1 diabetes was $60 \%$ while the specificity was $47 \%$. The PPV (positive predictive value) and the NPV (negative 
predictive value) were $55 \%$ and $67 \%$ respectively. Such results indicate that CD4 CD25 T-lymphocytes cannot be taken as a valid marker in case of type I diabetes.

There was no statistically significant difference between the 3 groups (diabetic - non diabetic siblings - controls) regarding CD4CD25 Tlymphocytes levels by the one-way ANOVA test.

Our results were consistent with those of Putnam et al., [9] who reported that there is no difference in the number of CD4CD25 T cells between type 1 diabetes patients and normal controls. Similarly, Brusko et al., [10] showed no differences were observed in the frequency of CD4CD25 T-cells in individuals with or at varying degrees of risk for type 1 diabetes. Their investigations suggest that altered peripheral blood frequencies of regulatory $\mathrm{T}$ cells, are not specifically associated with type 1 diabetes and continue to highlight age as an important variable in analysis of immune regulation.

Despite our finding that the frequency of regulatory $\mathrm{T}$ cells, does not appear to be deficient in type 1 diabetes, several caveats exist before we can definitely state that no differences in regulatory $\mathrm{T}$ cells are associated with type 1 diabetes. First, our study was conducted in peripheral blood and may not reflect the T-cell repertoire present at the site of inflammation (i.e., the pancreas and pancreatic draining lymph node). Furthermore, although the markers of CD25 represent appropriate markers identifying a lineage of regulatory $\mathrm{T}$ cells, additional phenotypic properties responsible for the functional capacity of regulatory $\mathrm{T}$ cells may be deficient in the case of type 1 diabetes. This could explain the normal frequency of regulatory $\mathrm{T}$ cells in our patients.

On the contrary, another study by GlisicMilosavljevic et al., [11] explained the decrease in the regulatory $\mathrm{T}$ cells was due to increased apoptosis of these cells in recent-onset type 1 diabetes subjects (all diagnosed within 1 st year) and in subjects at-risk for type 1 diabetes. This increase in regulatory $\mathrm{T}$ cells apoptosis was found to correlate with a decline in suppressive potential of these cells. The fact that both hyperglycemic type 1 diabetes subjects and normoglycemic at-risk subjects showed this phenomenon suggests that regulatory $\mathrm{T}$ cells apoptosis is more a precursor to, rather than a consequence of diabetes.

Stemming of this, Jailwala et al., [4] investigated the expression signature that shapes the transcrip- tional program within functionally deficient regulatory $\mathrm{T}$ cells from recent-onset type 1 diabetes. Expression profiles of regulatory $\mathrm{T}$ cells from type 1 diabetes subjects reveal a cellular response that could make the cells sensitive to apoptosis, partially due to deprivation of cytokines. This global picture of pathway-specific expression signatures is a step further into dissecting regulatory $\mathrm{T}$ cells dysfunction in the pathogenesis of type 1 diabetes. Meanwhile Yamanouchi et al., [12] hypothesized that reduced IL- 2 could be partially responsible for the increased apoptosis and reduced function of regulatory $\mathrm{T}$ cells from human type 1 diabetes subjects.

On the contrary to our results, MarekTrzonkowska et al. (2012) also reported that destruction of the pancreatic islets by self-reactive $\mathrm{T}$ cells is facilitated by deficits in the number and suppressive activity of regulatory $T$ cells and that their study showed for the first time that infusion of autologous regulatory $\mathrm{T}$ cells prolongs remission in recently diagnosed type 1 diabetes in children [13].

Males had a higher CD4 CD25 levels than females and difference was significant among the diabetic group but not in the other two groups with $p$-value $<0.05$.

Our data showed no significant difference between different categories of HBA1C metabolic control level as regard CD4 CD25 level among the diabetic patients.

Our results regarding the diabetic group showed no significant correlation of CD4 CD25 Tlymphocytes to age and the laboratory data including HBA1C, lipid profile or thyroid profile. In addition neither the insulin dose nor the severity of the case presentation (whether classic onset or DKA) had any statistically significant correlation with CD4 CD25 T-lymphocytes level with a $p$ value $>0.05$.

We found that there is no difference in the level of CD4 CD25 T regulatory cells between patients with type 1 diabetes, non diabetic siblings and healthy controls. This came in agreement with a study by Lindley et al., [3]. On doing numerical and functional studying and analyzing of CD4 CD25 T-cells, they assessed in-vitro cell interaction and release of interleukins and cytokines as indicator of functionality of CD4 CD25 T- cells. They showed that although the levels of CD4 CD25 cells regulatory $\mathrm{T}$ cells in patients with early onset type 1 -diabetes were normal, the ability of T-regs in this population to suppress $\mathrm{T}$-cell proliferation 
during in vitro co-cultures was markedly reduced compared with control subjects. Moreover, they found that in patients with type 1-diabetes these co-cultures displayed a more pro-inflammatory phenotype, with increased secretion of interferongama and decreased interleukin-10. They took these deficiency as reflection of a disturbance in the balance of $\mathrm{CD} 4 \mathrm{CD} 25$ population with other cells which they specified as CD69.

Thus, it appears highly desirable to preserve endogenous 0 cell mass and insulin production by interference with autoimmune responses prior to the destruction of the majority of insulin-producing 0 cells. However, the successful development of efficacious T1D prevention strategies will require detection of the earliest events in the autoimmune process. Schallenberg and Kretschmer [14] stated that it appears tempting to speculate that 0 cellresponsive naïve CD4+ $\mathrm{T}$ cells with a semicommitted TH-like phenotype may represent a suitable target for the assessment of early $\mathrm{T}$ cell responses to immune-modulating T1D prevention strategies, in particular tolerogenic vaccination with 0 cell antigen.

Recently, Heninger et al., [15] followed at-risk children from infancy and performed single-cell gene expression in 0 cell antigen-responsive CD4+ $\mathrm{T}$ cells through pre- and established autoimmune phases. A striking divergence in the gene signature of 0 cell antigen-responsive naïve CD4+ T cells from children who developed 0 cell autoimmunity was found in infancy, well before the appearance of 0 cell antigen-specific memory $\mathrm{T}$ cells or autoantibodies.

Several high-risk HLA haplotypes increase susceptibility to T1D, whereas the DR1501-DQ6 HLA haplotype confers dominant protection. Wen et al., [16] investigated the mechanistic basis for this protective effect by measuring the frequency of CD4+ T cells reactive with epitopes on islet autoantigens in healthy individuals. Individuals with the protective HLA haplotype had a higher frequency of islet antigen-reactive CD4+ T cells than individuals with high-risk or neutral haplotypes. These $\mathrm{CD} 4+\mathrm{T}$ cells included both regulatory $\mathrm{T}$ cells and effector $\mathrm{T}$ cells with a propensity to make IL-10. These findings provide deeper insights into how beneficial subsets of self-reactive $T$ cells maintain prophylaxis against autoimmunity.

Dwyer et al., [17] stated that regulatory $\mathrm{T}$ cells (Tregs) suppress autoreactive effector T cells to prevent the occurrence of autoimmune diseases, such as type 1 diabetes (T1D). The cytokine inter- leukin-2 (IL-2) is critical for the development and homeostasis of Treg subsets. Polymorphisms in the genes encoding IL-2 and its receptor subunits are associated with an increased risk of developing autoimmunity.

Marek-Trzonkowska $\mathrm{N}$ et al., hypothesized that CD4(+) CD25(+) FoxP3(+) regulatory T cells (Tregs) can prevent destruction of pancreatic islets protecting from type 1 diabetes (T1D). He presented results of one year follow-up of T1D children treated with autologous expanded ex vivo Tregs. Patients received either a single or double Tregs infusion. The treatment did not impair postimmunization antibody responses. Tregs infusion was followed by increase in Tregs number in peripheral blood. Most of the patients responded to the therapy with increase in C-peptide levels. Tregs administration resulted also in lower requirement for exogenous insulin. Repetitive administration of Tregs is safe and can prolong survival of 0 -cells in DM 1 [18].

Ghoniamshowed that diminished Treg in T1D proved that auto-reactivation of T-cell as a result of the breakdown of immune tolerance takes part in the elaboration of autoimmune disorders as T1D. Treg may be used in immunotherapy, thus preventing T1D development due to its pivotal role in immune tolerance [19].

Zimmer stated that a rogue hybrid lymphocyte, bearing characteristics of both $\mathrm{B}$ and $\mathrm{T}$ cells, may play a role in driving autoimmunity in the disease, although the mechanism is far from clear. Scientists have now discovered a novel type of lymphocyte in T1D patients that combines characteristics of B cells and T cells. He suggested that these hybrids could play an important role in the disease by encouraging the immune system to attack the body's own insulin-producing cells [20].

Gliwin'ski et al., concluded that in T1D, autoaggressive $\mathrm{T}$ cells (Tconventional cells, Tconvs) not properly controlled by Tregulatory cells (Tregs) destroy pancreatic islets. Thus, T1D is associated with immunosenescence-like changes and reduced diversity of T-cell clones. Preferential expansion of the same TCR families in both Tconvs and Tregs suggests a common trigger/autoantigen responsible. Interestingly, the therapy with polyclonal Tregs was associated with some inhibition of these effects. Proinsulin-specific Tregs appeared to be dominant in the immune responses in patients with T1D and probably associated with better control over respective autoimmune Tconvs [21] 
Barcellina et al., showed that subpopulations of Treg and NK cells were increased in individuals positive for multiple autoantibodies before onset of T1D. His results showed alterations of a subset of Tregs and NK cells in individuals with high risk for $\mathrm{T} 1 \mathrm{D}$. Using a multidimensional phenotyping and unbiased clustering approach to identify cell populations expressing markers which are not often analyzed in a conventional flow cytometry panel [22].

Kent and Babon stated thatmajority of information on autoreactive T cells in human T1D has come from the study of peripheral blood of donors with T1D. It is not clear how representative the peripheral autoreactive T-cell repertoire is of the autoreactive T cells infiltrating the islets in T1D. Immunohistopathology of insulitis, showed a broad range of autoreactive CD4+ and CD8+ T cells, with reactivity to known islet-associated peptides and posttranslationally modified peptides, infiltrate the islets and have a proinflammatory phenotype, was identified [23].

Michels et al., identified hundreds of T cells from inflamed pancreatic islets of three young organ donors with T1D with a short disease duration with high-risk HLA genes using a direct T-cell receptor (TCR) sequencing approach without longterm cell culture. These B: 9-23-specific T cells from islets responded to whole proinsulin and islets, whereas previously identified B: 9-23 responsive clones from peripheral blood did not, highlighting the importance of proinsulin-specific $\mathrm{T}$ cells in the islet microenvironment [24].

Delong et al., proved that pathogenic CD4 T cells target peptide ligands that are formed by covalent crosslinking of proinsulin peptides to other peptides present in 0 -cell secretory granules. These hybrid insulin peptides (HIPs) are highly antigenic for CD4 $\mathrm{T}$ cells and can be detected by mass spectrometry in 0 -cells. CD4 T cells from the residual pancreatic islets of two organ donors who had T1D also recognize HIPs. The discovery that autoreactive $\mathrm{T}$ cells target hybrid peptides may explain how immune tolerance is broken in T1D [25].

\section{Conclusion:}

This study concluded that there is no alteration in the frequency of regulatory CD4 CD25 T cells in the peripheral blood of children with type 1 diabetes as compared to the results with the CD4 CD25 T-cells in the non diabetic siblings and control subjects.

\section{References}

1- THOMAS D., ZACCONE P. and COOKE A.: The role of regulatory $\mathrm{T}$ cell defects in type I diabetes and the potential of these cells for therapy. Rev. Diabet. Stud, 2 (1): 9-18, 2005.

2- ROEP B.O.: The role of T-cells in the pathogenesis of Type 1 diabetes: From cause to cure. Diabetologia, 46 (3): 305-21, 2003.

3- LINDLEY S., DAYAN C.M., BISHOP A., ROEP B.O., PEAKMAN M. and TREE T.I.M.: Defective Suppressor Function in CD4+CD25+ T-Cells From Patients With Type 1 Diabetes, Diabetes, 54: 92-99, 2005.

4- JAILWALA P., WAUKAU J., GLISIC S., JANA S. and EHLENBACH S.: Apoptosis of CD4+CD25high T cells in type 1 diabetes may be partially mediated by IL-2 deprivation. PLoS ONE, 4 (8): e6527, 2009.

5- HEROLD K.C., HAGOPIAN W., AUGER J.A., POUMIAN-RUIZ E., TAYLOR L., DONALDSON D., GITELMAN S.E., HARLAN D.M., XU D., ZIVIN R.A. and BLUESTONE J.A.: Anti-CD3 monoclonal antibody in new-onset type 1 diabetes mellitus. N. Engl. J. Med., 346: 1692-1698, 2003.

6- RILEY J.L., JUNE C.H. and BLAZAR B.R.: Human T regulatory cell therapy: Take a billion or so and call me in the morning. Immunity, 30: 656-665, 2009.

7- BAYATI F., MOHAMMADI M., VALADI M., JAMSHIDI S., FOMA A.M. and SHARIF-PAGHALEH E.: The Therapeutic Potential of Regulatory T Cells: Challenges and Opportunities. Front Immunol., Vol. 11: 585819 , 2020.

8- JONULEIT H., SCHMITT E., STASSEN M., TUETTENBERG A., KNOP J. and ENK A.H.: Identification and functional characterization of human CD4 CD25 T-cells with regulatory properties isolated from peripheral blood. J. Exp. Med., 193: 1285-1294, 2001.

9- PUTNAM A.L., VENDRAME F., DOTTA F. and GOTTLIEB P.A.: CD4+CD25high regulatory $\mathrm{T}$ cells in human autoimmune diabetes. J. Autoimmun., 24: 55-62, 2005.

10-BRUSKO T., WASSERFALL C., McGRAIL K., SCHATZ R., VIENER H.L. and SCHATZ D, et al.: No alterations in the frequency of FOXP3+ regulatory T-cells in type 1 diabetes. Diabetes, 56: 604-12, 2007.

11-GLISIC-MILOSAVLJEVIC S., WAUKAU J., JAILWALA P., JANA S. and KHOO H.J.: At risk and recent-onset type 1 diabetic subjects have increased apoptosis in the CD4+CD25+ T-cell fraction. PLoS ONE, 2: e146, 2007.

12- YAMANOUCHI J., RAINBOW D., SERRA P., HOWLETT S., HUNTER KAND, et al.: Interleukin-2 gene variation impairs regulatory $\mathrm{T}$ cell function and causes autoimmunity. Nat Genet, 39: 329-337, 2007.

13- MAREK-TRZONKOWSKA N., MYSLIWIEC M., DOBYSZUK A., GRABOWSKA M., TECHMANSKA I., JUSCINSKA J., WUJTEWICZ M.A., WITKOWSKI P., MLYNARSKI W., BALCERSKA A., MYSLIWSKA J. and TRZONKOWSKI P.: Administration of CD4+CD25 high CD127-regulatory T cells preserves $\mathrm{P}$-cell function in type 1 diabetes in children. Diabetes Care, 35 (9): 1817-20, 2012. 
14- SCHALLENBERG S. and KRETSCHMER K.: New insight into type 1 diabetes development: Resolving early diabetogenic $\mathrm{CD} 4+\mathrm{T}$ cell responses that precede seroconversion. Ann. Transl. Med., 6 (3): 58, 2018.

15- HENINGER A.K., EUGSTER A., KUEHN D., BUETTNER F., KUHN N., LINDNER A., et al.: A divergent population of autoantigen-responsive CD4+ T cells in infants prior to $P$ cell autoimmunity. Science Translational Medicine, Vol. 9: 378, 2017.

16- WEN X., YANG J., JAMES E., CHOW I.T., REIJONEN H. and KWOK W.W.: Increased islet antigen-specific regulatory and effector CD4+ T cells in healthy individuals with the type 1 diabetes-protective haplotype. Science Immunology, Vol. 5:44, 2020.

17- DWYER C.J., BAYER A.L., FOTINO C., YU L., CABELLO-KINDELAN C., WARD N.C., et al.: Altered homeostasis and development of regulatory $\mathrm{T}$ cell subsets represent an IL-2R-dependent risk for diabetes in NOD mice. Science Signaling, Vol. 10: 510, 2017.

18- MAREK-TRZONKOWSKA N., MYS'LIWIEC M., DOBYSZUK A., GRABOWSKA M., DERKOWSKA I., JUS'CIN'SKA J., OWCZUK R., SZADKOWSKA A., WITKOWSKI P., MLYNARSKI W., JAROSZ-CHOBOT P., BOSSOWSKI A., SIEBERT J. and TRZONKOWSKI P.: Therapy of type 1 diabetes with CD4(+) CD25 (high) $\mathrm{CD} 127$-regulatory $\mathrm{T}$ cells prolongs survival of pancreatic islets = results of one year follow-up. ClinImmunol., 153 (1): 23-30, 2014.

19- GHONIAM M.M., EL EDEL R.H., KAMAL ELDIEN S.M., ABO EL FOTOH W.M. and SALMAN S.S.: TRegulatory Cell Subsets in Children with Type 1 Diabetes Mellitus: Relation to Control of The Disease. Endocrine, Metabolic \& Immune Disorders - Drug Targets, Vol. 17, No. 2, 2017.
20- ZIMMER K.: Novel Type of Immune Cell Discovered in Type 1 Diabetes Patients. Scientist, 56950, 2019.

21- GLIWIN`SKI M., IWASZKIEWICZ-GRZES` D., WOL OSZYN-DURKIEWICZ A., TARNOWSKA M., ZALIN'SKA M., HENNIG M., ZIELIN'SKA H., DUKATMAZUREK A., ZIELKOWSKA-DEBSKA J. and ZIELIN’SKI M., et al.: Proinsulin-specific T regulatory cells may control immune responses in type 1 diabetes: Implications for adoptive therapy. BMJ Open Diab. Res. Care, 8: e000873. doi:10, 2020.

22- BARCENILLA 1H., ÅKERMAN L., PIH M., LUDVIGSSON J. and CASAS R.: Mass Cytometry Identifies Distinct Subsets of Regulatory T Cells and Natural Killer Cells Associated With High Risk for Type 1. DiabetesFront. Immunol., Vol. 10:982, 2019.

23- KENT S.C. and BABON J.A.: Narrowing in on the antiP cell-specific T cells: Looking 'where the action is' Curr. Opin. Endocrinol. Diabetes Obes., 24 (2): 98-102, 2017.

24- MICHELS A.W., LANDRY L.G., McDANIEL K.A., YU L., CAMPBELL-THOMPSON M., KWOK W.W., JONES K.L., GOTTLIEB P.A., KAPPLER J.W., TANG Q., ROEP B.O., ATKINSON M.A., MATHEWS C.E. and NAKAYAMACORRESPONDING M.: Islet-Derived CD4 T Cells Targeting Proinsulin in Human Autoimmune Diabetes, Diabetes, Vol. 66 (3): 722-734, 2017.

25- DELONG T., WILES T.A., BAKER R.L., BRADLEY B., BARBOUR G., REISDORPH R., KUMAR N., ELSO C.M., ARMSTRONG M., POWELL R.L., REISDORPH N., DeNICOLA M., BOTTINO R., POWERS A., HARLAN D.M., KENT S.C., MANNERING S. and HASKINS K.: Pathogenic CD4 T cells in type 1 diabetes recognize epitopes formed by peptide fusion, Science, Vol. 351 (6274): 711-714, 2016. 


\section{ع خلايا CD25CD اللمفاوية في الأطفال الذين يعانون مؤخراً

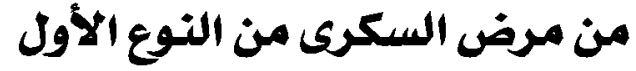

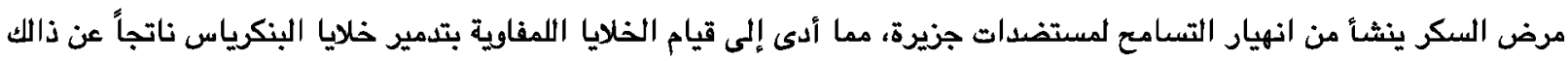

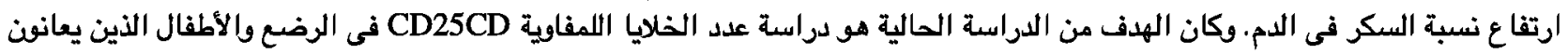

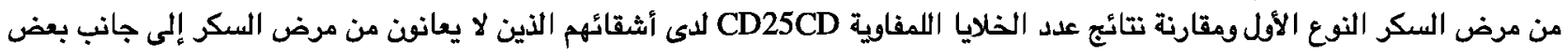
الأطفال المعافنن.

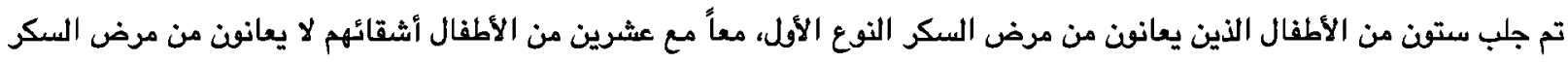

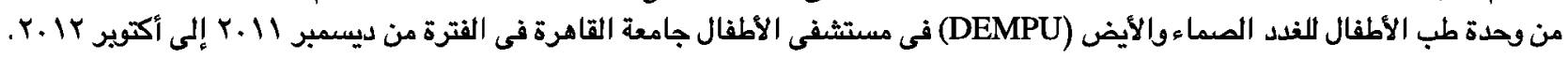

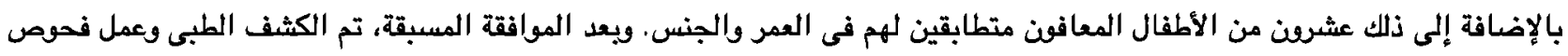

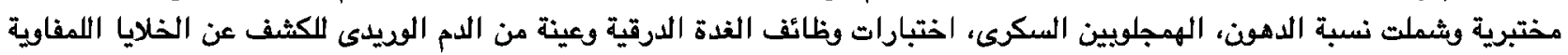

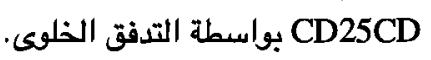

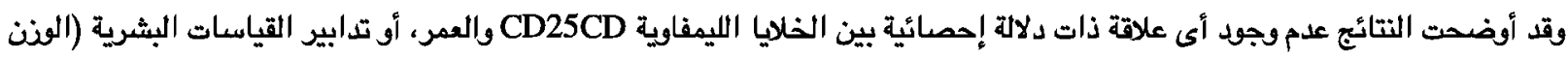

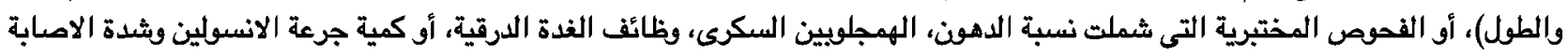

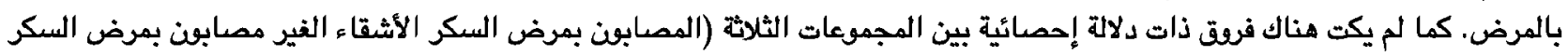

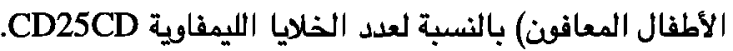

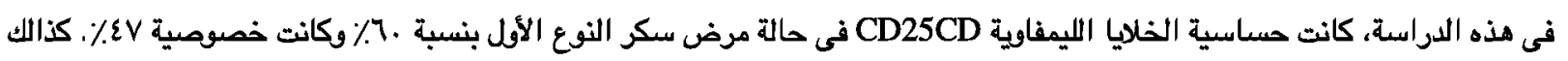

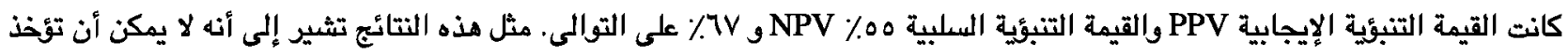

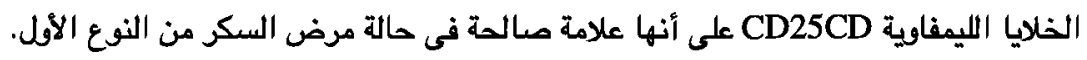

